\title{
Putting directionality into context ${ }^{1}$
}

\author{
Stefanie Dose \\ Department of Linguistics, University of Johannesburg, P.O. Box 524, Auckland Park 2006 \\ Email: sdose@uj.ac.za
}

\begin{abstract}
The question of directionality, i.e. whether (simultaneous) interpreters should work only from their second into their first language or whether the opposite direction is equally acceptable or even preferable, remains controversial. Although the issue has received much attention, the results of empirical studies are often conflicting, as evidence in support of both interpreting directions has been put forward. It has hence been suggested that interpreting direction may possibly be influenced by extralinguistic factors (Gile 2005). For the study reported on in this article, an analysis is carried out of the success with which interpreters recreate the source language speech's cohesive relations in their target language rendition. The results demonstrate that interpreting direction is not merely affected by at least one such variable, namely interpreters' familiarity with the context of the speech to be interpreted, but may in fact be totally outweighed by this variable.
\end{abstract}

Keywords: simultaneous interpreting, directionality, familiarity with the context, cohesion

\section{Introduction}

The term "directionality" in interpreting refers to the question of whether (simultaneous) interpreting should be performed only from a second or non-native language into a first or native language (firstlanguage interpreting), or whether interpreting from a first into a second language (second-language interpreting) can result in an equally successful interpreting performance.

Interpreting into a first language is often presumed to result in idiomatically flawless target language production (Seleskovitch 1978). Those who favour interpreting into a second language, on the other hand, believe that better comprehension of the source speech, and hence accuracy, can be achieved in this direction (Denissenko 1989). Despite an abundance of research on the topic, studies that attempt to identify the optimal interpreting direction often yield conflicting results: while some researchers find evidence in favour of the superiority of firstlanguage interpreting (Chang 2005, Darò, Lambert and Fabbro 1996), others show that secondlanguage interpreting results in an equally or even more successful interpreting performance (Tommola and Helevä 1998, Tommola and Laakso 1997). Some scholars have therefore

\footnotetext{
${ }^{1}$ This study is based on doctoral research currently being conducted at the University of the Witwatersrand.
} 
suggested that interpreting direction may not be the only, or even the main, factor in predicting interpreting performance, but that other variables may instead influence interpreters' performance in both interpreting directions (Gile 2005), thus accounting for the conflicting findings evident in the literature.

This article determines the effect that one such variable, namely interpreters' familiarity with the context of the speech to be interpreted, has on interpreters' performance in the two interpreting directions. The article presents evidence that interpreters' familiarity with the context not only compensates for, but in some respects totally outweighs the linguistic advantages and disadvantages of any one interpreting direction.

In order to examine the effects of familiarity with the context on different interpreting directions, an analysis is conducted of the performances of eight interpreters during a simultaneous interpreting examination following an intensive eight-week postgraduate short course at the University of the Witwatersrand. Participants are recorded interpreting speeches into both their first and second languages, with the speeches (and thus interpretations) being on familiar as well as unfamiliar topics. Their four individual performances are then compared according to the extent to which the interpreters successfully recreate in their target language renditions the cohesive ties pertaining to the source speeches.

\section{Directionality in interpreting}

Many studies on directionality in interpreting aim to shed some light on the differences between the two interpreting directions. Although directionality has received attention from researchers for several decades and has been approached from many different angles, no consensus on the matter has been reached.

Some theorists have argued that in order to produce satisfactory target language output, interpreters must interpret exclusively into their first language (Seleskovitch 1978). Harris (1989:116) lists the "norm taught in Western European interpreter schools that interpreters should only work into their A language" which, according to him, could even be called a dogma, as the third of his suggested norms in interpreting. This conviction is based on the assumption that linguistically flawless output can only be produced when interpreting into a native language, and that it is not possible to produce faultless language, especially under stressful conditions such as those characteristic of simultaneous interpreting, in a non-native language.

The alleged superiority of first-language interpreting has, however, been contested by others who claim that interpreting into a second language is indeed an acceptable practice and may in fact be the preferable direction (Denissenko 1989). These proponents of second-language interpreting claim that this interpreting direction guarantees perfect source language comprehension and therefore a higher level of accuracy and completeness, which is arguably more important in interpreting than linguistically flawless target language speech.

However, supporters of first-language interpreting respond to the above argument by pointing out that professional interpreters already possess perfect comprehension and analysis skills in their non-native source languages, which consequently ensure accuracy and completeness during first-language interpreting. 
Another less obvious argument that supports second-language interpreting includes the supposition that some, especially non-native, listeners may prefer listening to the arguably less idiomatic rendition of a non-native interpreter (Kalina 2005). On the other hand, Viaggio (1994) argues in support of first-language interpreting that perfect linguistic understanding of the source speech, supposedly granted during second-language interpreting, may not necessarily result in higher interpreting quality, and that it is in fact more difficult for interpreters listening to a native source speech to detach themselves from the linguistic form of the message.

In order to provide evidence in support of or against either of the above theoretical arguments, attempts have been made to determine empirically whether first-language interpreting does indeed result in a more successful interpreting performance than second-language interpreting. However, these studies do not provide the desired clear-cut answer.

On the one hand, some researchers provide empirical evidence in favour of first-language interpreting. Studies by Darò et al. (1996) and Chang (2005) indicate that interpreters, as traditionally argued, make more language use errors during second- than during first-language interpreting. Interestingly, however, it emerges that this direction can also lead to more meaning-based errors, resulting in lower accuracy and completeness of the target language message. Donovan (2004) confirms that major failures, such as a loss of complete ideas and unfinished sentences, can be observed more frequently during second-language interpreting. These studies therefore demonstrate that second-language interpreting can result in poorer quality regarding not only the linguistic features but also the accuracy and completeness of interpreters' output.

On the other hand, Lee (2003, cited in Chang 2005) demonstrates in favour of second-language interpreting that Korean/English trainee interpreters make more meaning-based errors when interpreting into their first language, and more language-based errors when interpreting into their second language, arguably because of better target language production and monitoring skills during first-language interpreting, and better source language comprehension and memory capacity in second-language interpreting. The studies by Tommola and Laakso (1997) and Tommola and Helevä (1998) are consistent with this finding, as they observe higher propositional accuracy during second-language interpreting performances by Finnish/English trainee interpreters. Finally, Al-Salman and Al-Khanji's (2002) data suggests that Arabic/English interpreters achieve successful informational transfer more often during secondlanguage interpreting. This finding suggests that accuracy and completeness of the target language message are more likely to be achieved during second-language interpreting, contradicting the findings of the studies by Darò et al. (1996) and Chang (2005) mentioned above.

Like the theoretical arguments regarding directionality, empirical studies too produce contradictory results. A possible explanation for these inconsistent findings is that other variables apart from interpreting direction have affected interpreters' performances in the individual studies. Gile (2005:17) explains that "[i]t is possible, and even plausible, that the effects of language mastery are smaller, and sometimes much smaller, than the effects of other variables".

Some studies on directionality in interpreting provide more specific clues regarding the particular variables that should be considered in connection with interpreting direction, such as the amount of training received in a direction (Donovan 2004), the context of the source 
language speech (Chang 2005), listeners' linguistic backgrounds (Gile 1990), interpreters' levels of expertise (Barik 1994, Bartłomiejczyk 2004) and the language combination under examination (Al-Salman and Al-Khanji 2002, Kurz and Färber 2003).

\section{Familiarity with the context}

It has furthermore been suggested that interpreters' performances in different interpreting directions may be affected by interpreters' extralinguistic knowledge in the field discussed in the speech to be interpreted. Clients of interpreting services surveyed in Donovan (2002), for example, while indifferent towards interpreting direction, highlight the fact that they prefer interpreters who are familiar with the context of the speech that they are interpreting. In line with this, Gile (1993:71) argues that "the better the extralinguistic knowledge, the less knowledge of the language is required to reach the same level of comprehension" (given that the interpreter possesses some, as yet undetermined, minimum level of each).

The benefits of extralinguistic knowledge or context familiarity as such on interpreting performance have been affirmed by interpreters as well as theorists. Several studies provide evidence in support of this: Al-Salman and Al-Khanji (2002), for example, observe that interpreters employ more successful communication strategies when they are familiar with the context of the speech to be interpreted. Vuorikoski (2004:236) observes a higher number of omissions and errors in cases in which the context is unfamiliar to the interpreter, concluding that "accuracy is influenced [...] by the interpreter's knowledge of the subject". While Anderson (1994) concludes on the basis of her data that prior exposure to the context of a speech does not improve the performance of participants (measured according to the intelligibility and informativity of the target language rendition), she concedes that the speeches used in her study were extremely general in nature, and that more pronounced effects of context familiarity on interpreting performance may only be observed when interpreters are presented with more specialised source language speeches.

However, it is not clear whether and to what extent context familiarity affects the two interpreting directions in different ways. While it is plausible to assume that a greater understanding of the extralinguistic context may compensate to some extent for an interpreter's gap in second-language comprehension and production proficiency, no evidence to this effect has to date been provided. This article demonstrates that interpreters' familiarity with the context may not only compensate for certain production gaps during second-language interpreting, but may, in certain respects, entirely outweigh any possible effects of interpreting direction. The study focuses on interpreters' familiarity with the "specialised context" of the source language speech, described by Setton (2006:379) as consisting of the interpreter's technical knowledge of the topic.

\section{Cohesion in interpreting}

One of the features that may be affected by interpreting direction and by familiarity with the specialised context of the source language speech is the cohesion of the interpreted target language speech. While little research has been done on how simultaneous interpreters create cohesion in their target language output, the study of cohesion in translated text has received extensive attention from scholars. Parallel studies comparing source and target texts have found that the translation process can lead to shifts in cohesion between a source text and its translation (Blum-Kulka 
1986/2002). On the other hand, comparable studies that compare translated and non-translated texts have provided some evidence that the cohesive patterning in translated texts may differ from the cohesive patterning in non-translated language (Olohan and Baker 2000).

The above findings for translated text need not necessarily apply to simultaneously interpreted speech as interpreters work in different environments, are subject to different constraints and often apply different strategies from those typically employed in translation. However, studies of interpreted speech provide evidence which suggests that the way in which interpreters recreate source speech cohesive ties may be affected by interpreting direction and interpreters' familiarity with the context, both affecting cohesion in their own individual ways.

Gumul (2006), for example, finds that student interpreters use more explicitation (including the addition of connective devices that make source speech cohesive networks more explicit) during second- than during first-language interpreting. She attributes the higher occurrence of explicitation during second-language interpreting to the participants' problems in finding appropriate stylistic equivalents in their non-native target language (Gumul 2006:slide 28).

Shlesinger (1995), on the other hand, discovers that student interpreters' prior exposure to a speech (and hence a presumably increased level of familiarity with it) may also affect the way in which interpreters transfer the source speech's cohesive ties into the target speech. Her data shows that "when the interpreter has enjoyed prior exposure to the text, the proportion of omissions and errors [regarding cohesive devices] will be reduced" (Shlesinger 1995:212).

Apart from being influenced by both interpreting direction and interpreters' familiarity with the context, cohesion - together with sense consistency with the original message - is also considered of major importance for the perceived quality of the interpreted product by both interpreters themselves and by different user groups, as ascertained in a survey conducted by Kurz (1993). An analysis of the recreation of source speech cohesion in the target language thus constitutes a worthwhile endeavour. The following sections therefore examine whether and to what extent interpreting direction and familiarity with the specialised context interact regarding interpreters' success in recreating the source speech's cohesive ties, and in particular those expressed by causal and adversative conjunctions in the source language speech.

\section{Data}

The data analysed in this article consists of recordings of eight interpreters sitting a simultaneous interpreting examination following the eight-week intensive short course "Introduction to Conference Interpreting"2 conducted at the Wits Language School at the University of the Witwatersrand in September 2012. The course, conducted by an interpreter trainer accredited with the International Association of Conference Interpreters (AIIC), was taught via blended learning, with a six-week online component followed by a two-week masterclass and an examination. The course bears credit towards an Honours or a Masters in Interpreting, and contains a similar number of notional study hours as a semester course taught once a week.

\footnotetext{
${ }^{2}$ The name of the course has since changed to "Conference Interpreting Skills".
} 
Due to the difficulties associated with administering language tests to native and near-native speakers as discussed by, for example, Chang (2005), the participants' language dominance and extralinguistic backgrounds were instead assessed during interviews based on the Language Experience and Proficiency Questionnaire developed by Marian, Blumenfeld and Kaushanskaya (2007). The interviews were conducted throughout the duration of the course. Table 1 below provides an overview of the participants' language and extralinguistic backgrounds. Four interpreters speak French as their first language and English as their second language, three interpreters speak Afrikaans as their first and English as their second language, and one interpreter speaks German as her first and English as her second language.

Table 1. Participants' language and extralinguistic backgrounds

\begin{tabular}{|c|c|c|c|c|c|}
\hline Interpreter & L1 & L2 & $\begin{array}{c}\text { Interpreting } \\
\text { experience }\end{array}$ & $\begin{array}{c}\text { Other work / study } \\
\text { experience }\end{array}$ & $\begin{array}{c}\text { Regularly } \\
\text { interprets }\end{array}$ \\
\hline A1m & Afr & Eng & $\begin{array}{c}\text { Yes, mainly into } \\
\text { L2 }\end{array}$ & Law & $\begin{array}{c}\text { Law, sports, } \\
\text { engineering }\end{array}$ \\
\hline A2m & Afr & Eng & $\begin{array}{c}\text { Yes, in both } \\
\text { directions }\end{array}$ & Education & $\begin{array}{c}\text { Physiology, } \\
\text { pharmacy, } \\
\text { economics }\end{array}$ \\
\hline A3f & Afr & Eng & $\begin{array}{c}\text { Mainly training, } \\
\text { both directions }\end{array}$ & Translation & - \\
\hline F1m & Fr & Eng & $\begin{array}{c}\text { Yes, in both } \\
\text { directions }\end{array}$ & Business administration & Agriculture \\
\hline F2m & Fr & Eng & $\begin{array}{c}\text { Yes, in both } \\
\text { directions }\end{array}$ & Law, marketing & Politics \\
\hline F3m & Fr & Eng & $\begin{array}{c}\text { Yes, in both } \\
\text { directions }\end{array}$ & $\begin{array}{c}\text { Health, } \\
\text { policy }\end{array}$ \\
\hline F4f & Fr & Eng & $\begin{array}{c}\text { Mainly training, } \\
\text { both directions }\end{array}$ & $\begin{array}{c}\text { Psychology, journalism, } \\
\text { translation }\end{array}$ & - \\
\hline G1f & Ger & Eng & $\begin{array}{c}\text { Yes, mainly into } \\
\text { L2 }\end{array}$ & Translation & $\begin{array}{c}\text { Engineering, } \\
\text { pharmacy, } \\
\text { economics }\end{array}$ \\
\hline
\end{tabular}

For the purposes of the examination, each participant had to simultaneously interpret four different speeches, each approximately ten minutes in length. Two speeches had to be interpreted into a first language and two speeches into a second language. For each interpreting direction, one speech represented a topic with which the participants were familiar and one speech represented a topic with which the participants were unfamiliar. The four examination speeches therefore represent the following four interpreting situations:

(a) Into L1, familiar topic

(b) Into L1, unfamiliar topic

(c) Into L2, familiar topic

(d) Into L2, unfamiliar topic

The topics of the familiar context speeches were practised extensively during the course preceding the exams. The interpreters are therefore considered more familiar with the specialised context of these particular speeches due to the intensive training received in 
interpreting speeches on these topics. (In order to confirm that participants were not otherwise familiar with the topics of the unfamiliar context speeches, the interviews referred to above also included questions to determine the participants' backgrounds in fields other than interpreting as well as the fields for which they typically interpret.)

The topics that are addressed in the familiar speeches include the fall of the Berlin Wall (Afrikaans source speech), economic development in Africa (English source speech), women's rights (French source speech), and civil aviation (German source speech). The unknown topic speeches deal with Halaal signs on food packaging (Afrikaans source speech), human evolution (English source speech), the physical properties of the egg shell (French source speech), and self-steering cars (German source speech). The speeches were selected by the examiner and were pre-recorded. All speeches are comparable in length; however, not all speeches are comparable regarding source speech input rate and lexical density, a shortcoming of the study which may cause differences in interpreter performance.

All source and target language recordings have been transcribed according to EPIC transcription conventions (SSLMIT 2004) but excluding paralinguistic features (which are not examined in the present study). The parallel corpus tool ParaConc269 (Barlow 2003) is employed to identify the relevant source language segments along with their corresponding target language renditions. In the following sections, the participants' performances in the four interpreting situations are examined through an analysis of the participants' success in recreating source speech cohesive ties in the different interpreting situations.

\section{Recreation of cohesive ties}

The analysis in this section focuses on the recreation of the adversative and causal relations present in the source language speeches. After the relevant source language segments containing adversative and causal relations have been identified in the source speeches, all segments are reviewed manually in order to verify their function, as some devices (such as since) may fulfil different cohesive functions. The cohesive devices listed in Table 2 appear in the relevant source language speeches: 
Table 2. Cohesive devices in source language speeches

\begin{tabular}{|c|c|c|}
\hline & Adversative devices & Causal devices \\
\hline $\begin{array}{l}\text { Afrikaans source } \\
\text { speeches } \\
\text { Adversative (16) } \\
\text { Causal (7) }\end{array}$ & $\begin{array}{l}\text { egter ('however') (9) } \\
\text { maar ('but') (6) } \\
\text { terwyl ('whereas') (1) }\end{array}$ & $\begin{array}{l}\text { dus ('thus') (2) } \\
\text { omdat ('because') (1) } \\
\text { aangesien ('seeing that') (1) } \\
\text { derhalwe ('therefore') (1) } \\
\text { redes waarom ('reasons why') (1) } \\
\text { ten einde ('in order to') (1) }\end{array}$ \\
\hline $\begin{array}{l}\text { English source } \\
\text { speeches } \\
\text { Adversative (13) } \\
\text { Causal (9) }\end{array}$ & \begin{tabular}{|l|} 
but $(8)$ \\
however (2) \\
though (2) \\
whereas (1)
\end{tabular} & $\begin{array}{l}\text { so (4) } \\
\text { because (2) } \\
\text { that's why (1) } \\
\text { since (1) } \\
\text { then (1) }\end{array}$ \\
\hline $\begin{array}{l}\text { French source } \\
\text { speeches } \\
\text { Adversative (9) } \\
\text { Causal (7) }\end{array}$ & mais ('but') (9) & $\begin{array}{l}\text { donc ('therefore') (3) } \\
\text { c'est pourquoi ('that's why') (1) } \\
\text { afin ('in order to') (1) } \\
\text { par ('by') (1) } \\
\text { [estompe] avec [l'augmentation] } \\
\text { ('[wears away] as [... increases]') (1) }\end{array}$ \\
\hline $\begin{array}{l}\text { German source } \\
\text { speeches } \\
\text { Adversative (8) } \\
\text { Causal (7) } \\
\end{array}$ & $\begin{array}{l}\text { sondern ('but') (4) } \\
\text { allerdings ('however') (3) } \\
\text { aber ('but') (1) }\end{array}$ & $\begin{array}{l}\text { denn ('since') (2) } \\
\text { deshalb ('therefore') (2) } \\
\text { weil ('because') (2) } \\
\text { um ('in order to') (1) }\end{array}$ \\
\hline
\end{tabular}

The target language renditions aligned with the relevant source speech segments are subsequently located in the transcriptions of the interpreters' output using ParaConc269 (Barlow 2003). The source speech's cohesive ties are then compared to the type of cohesion created by the interpreter in the corresponding target language segment. The comparison between source and target language segments leads to the classification of the interpreters' renditions into six main categories of strategies that the interpreters in the present study have employed in order to render the source speech cohesive ties in the target language. These strategies are explained in (a) to (f) below:

\section{(a) Retention of conjunction}

The interpreter employs a direct target language equivalent of the conjunction or phrase used in the source language.

\section{Example 1: Afrikaans $\rightarrow$ English; The fall of the Berlin Wall (A1m)}

- SL: ... die probleem was nie die bewese be- uh verrigtingsvoertuig van vrye markte nie [[maar]] die roekelose manier waarop daardie voertuig bestuur is dikwels deur die verkeerspolisie self ...

- Back translation: ... the problem was not the pr- uh proven vehicle of free markets [[but $]]$ the reckless manner in which that vehicle was driven, often by the traffic police themselves ...

- $\quad$ TL: ... the problem was not so much the vehicle of free market [[but]] rather the reckless way in which that vehicle was driven quite often by the traffic police themselves ... 


\section{(b) Use of a different conjunction with the same or a similar cohesive function}

The interpreter does not use a direct target language equivalent of the source language conjunction but a different conjunction or phrase that establishes the same cohesive relation as the one pertaining to the source speech.

\section{Example 2: Afrikaans $\rightarrow$ English; Halaal signs on food packaging (A2m)}

- SL: ... en dat deur die oorvloedige beskikbaarheid daarvan in onbe- uh openbare handelkleinhandelswinkels die keusevryheid van Christene ingeperk word en dit [[dus]] neerkom op diskriminasie // dit geld ook wat betref die tekens van ander gelowe op kosprodukte ...

- Back translation: ... and that as a result of the excessive availability of this in un- uh public retail stores the freedom of choice for Christians is limited and it [[thus]] comes down to discrimination // this also applies to the signs of other religions on food products ...

- TL: ... the small retailers must then have the uh will then limit the choice of Christians and [[then]] it comes down to discrimination // it also includes the symbols of other religions on food products ...

\section{(c) No conjunction}

The interpreter does not use any cohesive conjunction or phrase; the cohesive relationship between the relevant elements is therefore left implicit (but not in any way altered).

Example 3: English $\rightarrow$ French; Human evolution (F3m)

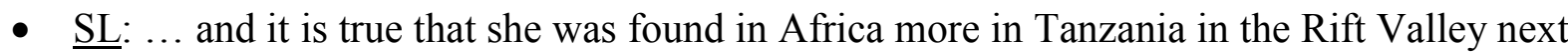
to Ngorongoro Crater // [[but]] now we have to see how humans have gone through the evolution ...

- TL: ... et et et on l'a connu en Afrique dans la vallée dans une valleé de la Tanzanie // [[- - -]] maintenant nous devons nous allons voir comment l'évolution l'évolu- l'évolution du genre humain s'est produite ...

- Back translation: ... and and and she was found in Africa in the valley in a valley in Tanzania // [[- - - ]] now we need to we will see how the evolution the evolu- the evolution of the human species has come about ...

\section{(d) Reformulation}

The interpreter reformulates the source language segment in such a way that the source language cohesive device is rendered unnecessary. In the following example, the idea of promoting and protecting human rights in the source language speech is summarised by the interpreter, who refers to the more general idea of paying attention to human rights.

\section{Example 4: English $\rightarrow$ French; Economic development in Africa (F1m)}

- $\quad$ SL: ... this is demonstrated by the Foreign Secretary's commitment to a foreign policy in which the promotion [[and]] protection of human rights around the world ...

- TL: ... mais l'engagement du ministère des affaires étrangères de la Grande Bretagne est de prêter attention aux droits de l'homme à travers le monde ... 
- Back translation: ... but the British ministry of foreign affairs is committed to paying attention to human rights around the world ...

(e) Omission of segment

The interpreter does not use any cohesive device because the entire source language segment has been omitted. The target language message may or may not be logically cohesive; part of the meaning has been lost.

Example 5: English $\rightarrow$ French; Economic development in Africa (F4f)

- SL: ... and it is demonstrated by our plans to devote zero point seven per cent of our gross national income to international aid from two thousand and thirteen [[despite]] these tough economic times // indeed we are the first country in the G twenty to set out exactly how we will do so ...

- TL: ... zéro virgule sept pour cent de nos revenus sont dévoyés ou dévolus uh à l'Afrique pour les aider [[- - -]] // la prochaine mit- mission le prochain sommet de G vingt portera sur comment est-ce qu'on pourrait améliorer les conditions en Afrique ...

- Back translation: ... zero comma seven per cent of our revenues are diverted or allocated uh to Africa to help them [I- - - ] // the next mit- mission, the next G twenty summit will deal with how we could improve conditions in Africa ...

\section{(f) Different cohesive relationship}

The interpreter uses a cohesive device that creates a different cohesive function. As a result, the cohesive relationship in the target text differs from the one conveyed in the source speech. (In the example below, the relation between the two clauses in the source language speech is adversative; however, it becomes causal in the target language rendition.) This category also includes those omissions and reformulations that result in a cohesive relationship different from the one pertaining to the source speech.

Example 6: Afrikaans $\rightarrow$ English; Halaal signs on food packaging (A1m)

- $\underline{\mathrm{SL}}:$... die omset van die wêreldmark waarvan Suid-Afrika die vyfde grootste bydraer is word beraam op twee komma vyf triljard uhm uh VSA-Dollar // dit [[terwyl]] die SuidAfrikaanse Moslems minder as nul punt nul vyf van die Moslem-bevolkings wêreldwyd uitmaak ...

- Back translation: ... the turnover of the world market of which South Africa is the fifth largest contributor is estimated at two comma five trillion US Dollar // that [[while]] South African Muslims account for less than zero point zero five of the Muslim populations worldwide ...

- TL: ... the turnover the world market of which South Africa ha- is the fifth largest contributor comes down to one comma five trillions of Rands or rather Dollars // [[that means that]] the South African Muslims contribute less than zero point zero five per cent of the world's Muslim population ...

Strategies (a) to (d) are considered to result in a successful transfer of the source speech's cohesive networks. Although not all of these segments formally retain the cohesive device used by the source language speaker, from a functional perspective, cohesion is maintained in the 
target language rendition either through different means or by implication. On the other hand, strategies (e) and (f) are considered unsuccessful attempts at recreating the source speech's cohesive relationships in the interpreted rendition, as the relevant segment is either entirely omitted or the interpreter creates a cohesive relationship which differs from the one present in the source speech.

In the following sections, the percentages of successful and unsuccessful strategies employed while producing a particular rendition are compared across the different interpreting directions and levels of familiarity with the specialised context. Although the results were not tested for statistical significance, a difference of $5 \%$ or more between different interpreting performances by the same interpreter is considered to be an indication of a difference in performance; differences between successful and unsuccessful strategies of under 5\% are considered an indication of a similar degree of success at interpreting the various speeches under comparison. Each interpreter's four individual performances are analysed separately in section 6.1 in order to determine whether familiarity with the specialised context has an interpreting directionspecific effect on interpreter performance as far as the recreation of cohesive ties in the target language is concerned. Thereafter, all first- and second-language interpreting performances (regardless of the level of familiarity with the context) will be compared with each other in section 6.2, followed by a comparison of all familiar and unfamiliar context performances (regardless of interpreting direction) in section 6.3. Section 6.4 contrasts the interpreters' performance during first-language interpreting of an unfamiliar context speech and secondlanguage interpreting of a familiar context speech.

\subsection{Effect of familiarity with the context on first- and second-language interpreting}

Familiarity with the specialised context appears to have a similar impact on both first- and second-language interpreting as far as the interpreters' success in recreating source speech cohesive ties is concerned. A relative majority of the interpreters appear to benefit from familiarity with the context in both interpreting directions. Consider Figures 1a to d:

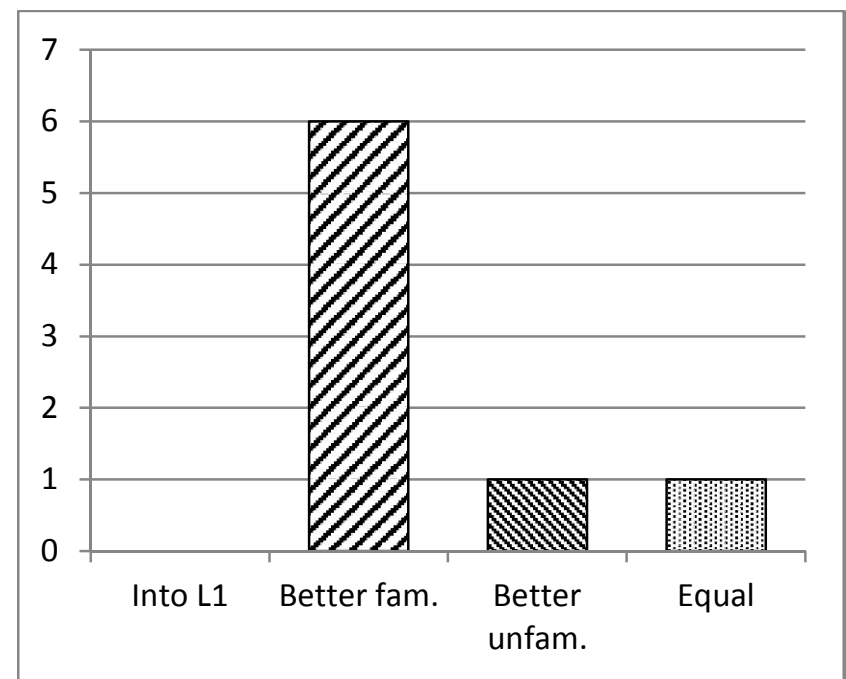

Figure 1a. Number of interpreters performing better during L1 interpreting when familiar with the context of the speech

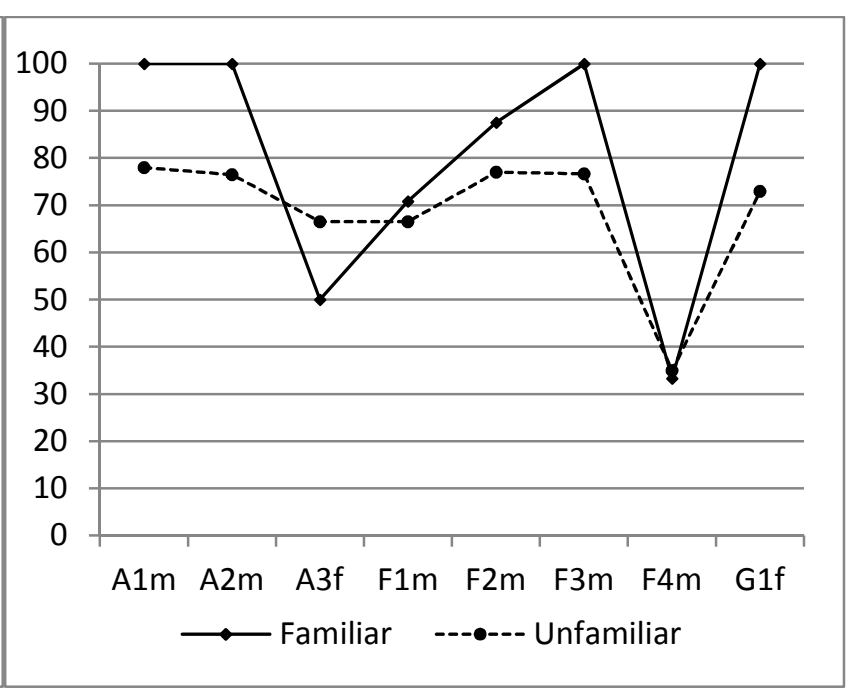

Figure 1b. Successful strategies (in \%) for interpreting familiar and unfamiliar context speeches into the L1 


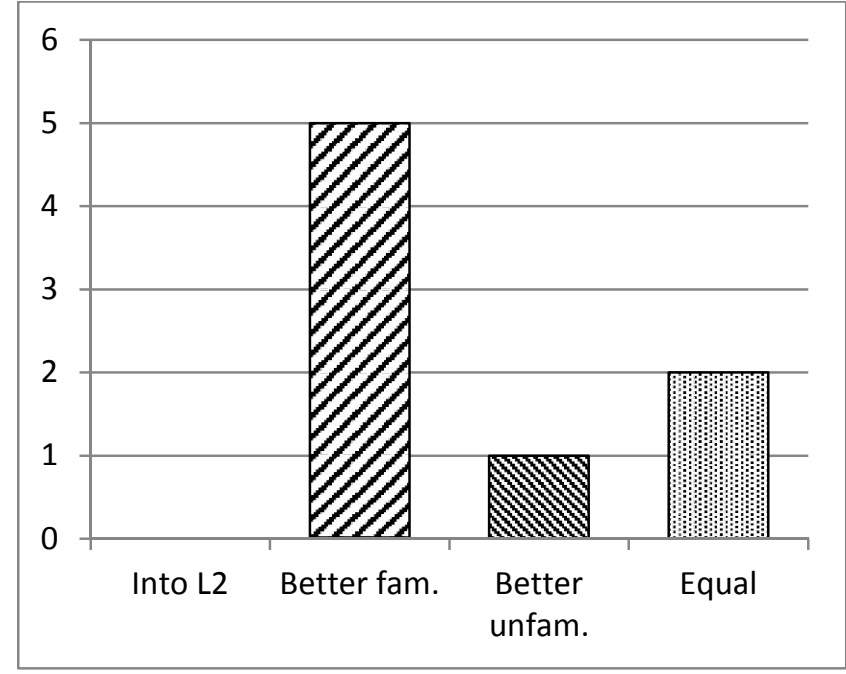

Figure 1c. Number of interpreters performing better during L2 interpreting when familiar with the context of the speech

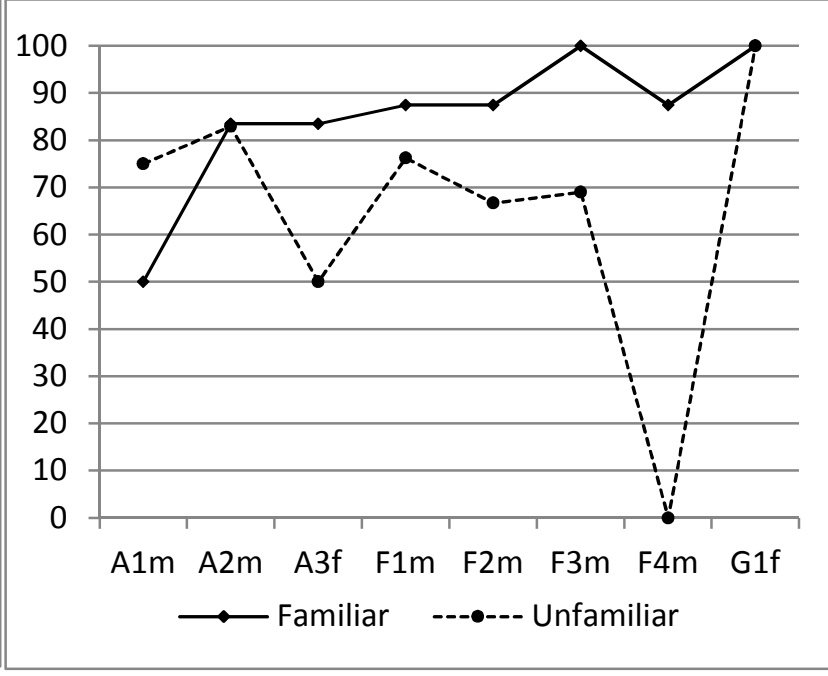

Figure 1d. Successful strategies (in \%) for interpreting familiar and unfamiliar context speeches into the L2

During first-language interpreting, as illustrated in Figure 1a, six interpreters perform better when interpreting the speech on a familiar context, one interpreter (A3f) performs better when interpreting the unfamiliar context speech, and one interpreter (F4f) performs equally well regardless of her familiarity with the specialised context of the source speeches. As the familiar and the unfamiliar English source language speeches are delivered at comparable rates (106 words per minute and 101 words per minute, respectively), this finding cannot be the result of differences in source speech input rates. The better performances when interpreting the familiar source language speech are furthermore achieved despite the fact that the familiar English source language speech confronts the interpreters with a higher lexical density $\left(\mathrm{L}_{d}=58\right)$ than the unfamiliar English source language speech $\left(\mathrm{L}_{\mathrm{d}}=48\right)$.

Figure 1c shows that during second-language interpreting, five interpreters perform better when they are familiar with the specialised context of the source speech, one interpreter (A1m) is more successful when interpreting the unfamiliar speech, and two interpreters (A2m, G1f) are equally successful regardless of their familiarity with the context.

Although a relative majority of the interpreters benefit from familiarity with the context in both interpreting directions, their level of familiarity has no interpreting direction-specific impact as far as the recreation of cohesive ties is concerned, as both interpreting directions similarly benefit from the interpreters' familiarity with the specialised context. (It may, however, be noted that the difference in performance between familiar and unfamiliar context, illustrated by Figures $1 \mathrm{~b}$ and $1 \mathrm{~d}$, is sometimes greater for second- than for first-language interpreting, suggesting that in some cases, second-language interpreting benefits to a greater extent from the interpreters' familiarity with the context than first-language interpreting.) However, it must be noted that the fact that the familiar French source language speech was delivered at a slower rate than the unfamiliar French source language speech may be partly responsible for the result that all the French interpreters perform better when interpreting the familiar French speech into their second language. On the other hand, an Afrikaans interpreter achieves a significantly higher score for interpreting the familiar Afrikaans speech into her second language despite its 
higher input rate (154 words per minute) when compared with the unfamiliar Afrikaans source speech (139 words per minute).

In order to determine whether interpreters' transfer of cohesive devices is affected by either one of the above two variables, the following two sections compare the interpreters' performance for both speeches interpreted into the first language with their performance for both speeches interpreted into the second language (section 6.2), and finally for interpreting both speeches on familiar topics and interpreting both speeches on unfamiliar topics (section 6.3).

\subsection{Interpreting direction}

Interpreting direction per se does not consistently affect the success with which interpreters recreate source speech cohesive relations in their target language output. Consider the figures below:

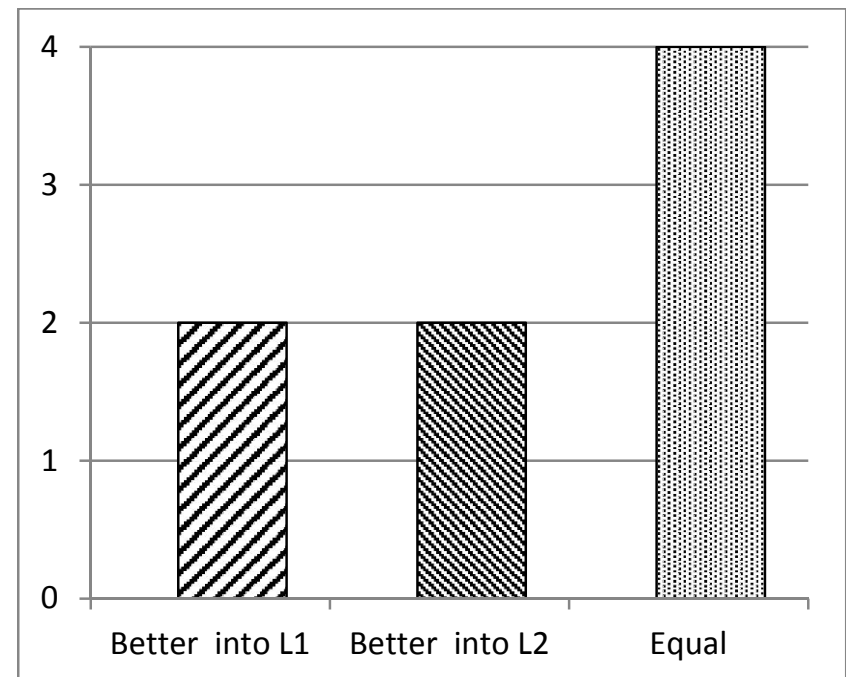

Figure 2a. Number of interpreters performing better in L1 and L2 interpreting

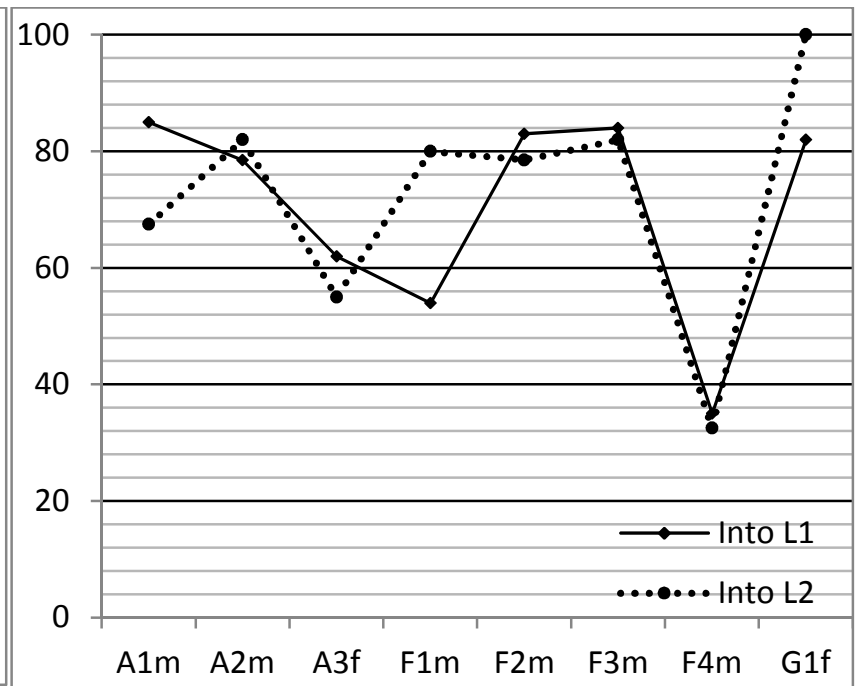

Figure 2b. Successful strategies (in \%) per interpreter for L1 and L2 interpreting

Figure 2a shows that two interpreters (A1m, A3f) use more successful strategies during firstlanguage interpreting than during second-language interpreting, two interpreters (F1m, G1f) are more successful during second-language interpreting and four interpreters (A2m, F2m, F3m, F4f) are equally successful in both interpreting directions. No effect of source speech input rate can be identified. Figure $2 \mathrm{~b}$ presents the percentage values of successful strategies that each interpreter achieved for the two interpreting directions. No consistent effect of interpreting direction on the interpreters' success at recreating source speech adversative and causal relations is evident ${ }^{3}$.

\subsection{Familiarity with the topic}

The interpreters' familiarity with the topic of the speech, on the other hand, has a strong effect on the interpreters' transfer of cohesive relations, as can be seen in Figure $3 \mathrm{a}$ below.

\footnotetext{
${ }^{3}$ Whether the participants in this study add cohesive devices to their output in order to make the target language rendition more explicitly cohesive than the source language speech during any one interpreting direction (as found in Gumul 2006) is not investigated in this study, as the present analysis only focuses on the way in which interpreters transfer cohesive relations that are present in the source language speech. The results therefore neither support nor contradict Gumul's (2006) findings.
} 


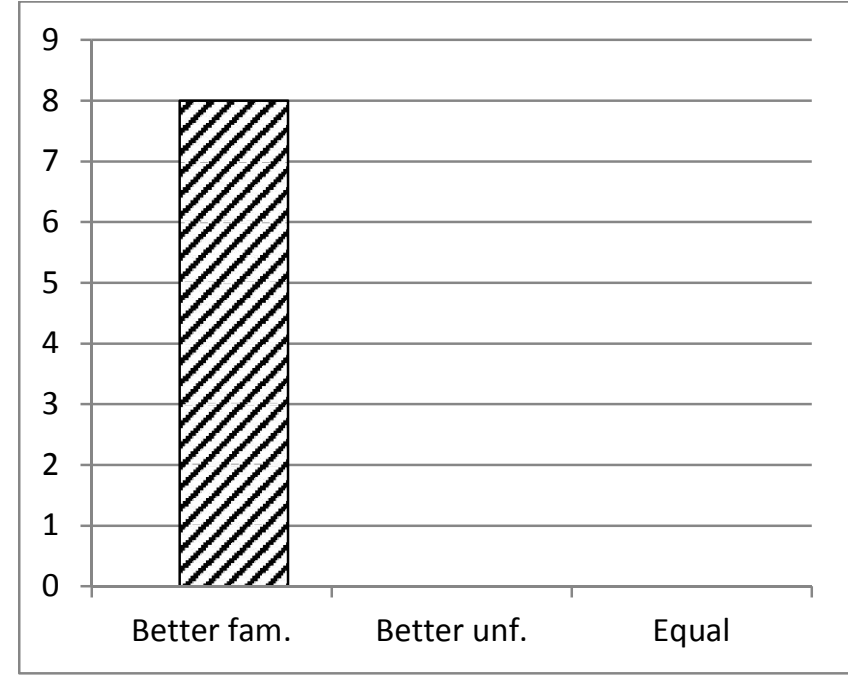

Figure 3a. Number of interpreters performing better for familiar and unfamiliar contexts

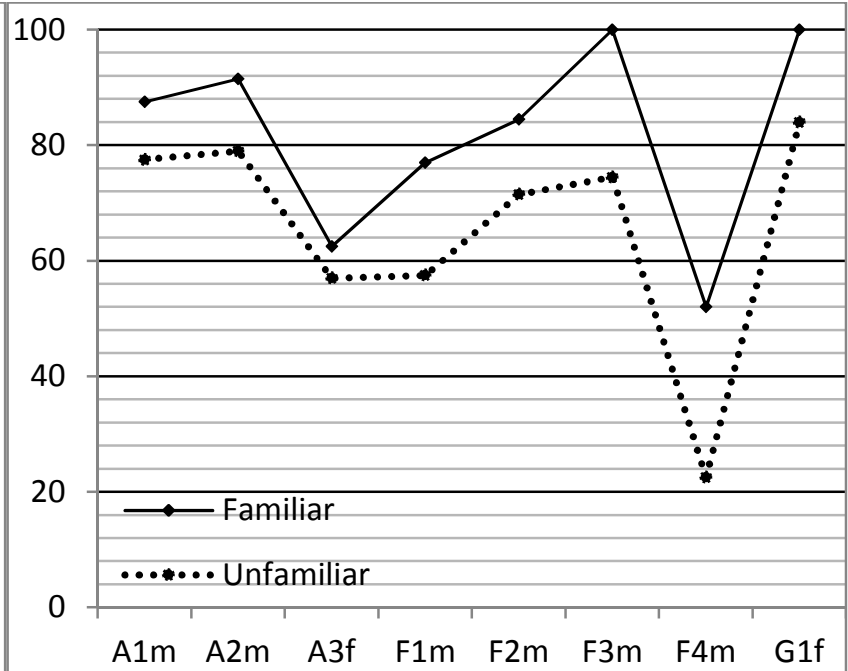

Figure 3b. Successful strategies (in \%) for familiar and unfamiliar contexts

Based on the combined values of both familiar and both unfamiliar speeches, all eight interpreters are more successful when interpreting speeches on the familiar topics compared to their renditions of speeches on the unfamiliar topics, regardless of source speech input rate, although for some interpreters the difference in performance is greater than for others (see Figure 3b). This confirms Shlesinger's (1995) finding that interpreters are more successful in recreating source speech cohesive relations when they have some degree of familiarity with the source speech. Whereas Shlesinger's (1995) participants had had prior exposure to the exact same speech to be interpreted, the present study indicates that interpreter training in a specific topic has similarly beneficial effects on interpreter performance.

It can therefore be concluded that familiarity with the topic of the speech to be interpreted, achieved through topic-specific interpreting training, positively affects interpreters' success in recreating source speech adversative and causal relations in the target language rendition whereas interpreting direction on its own has no consistent effect on this aspect of the interpreters' performance. The effects of an extralinguistic variable, namely familiarity with the topic, clearly are more significant as far as the interpreters' successful recreations of source speech cohesive relations are concerned, rendering considerations regarding interpreting direction less relevant in this respect.

\subsection{L1 interpreting of unfamiliar topics vs. L2 interpreting of familiar topics}

It is worth noting that when the interpreters' renditions of the first-language interpreting/unfamiliar topic speeches are compared to their renditions of the second-language interpreting/familiar topic speeches, seven of the eight interpreters in this study are more successful in recreating source speech adversative and causal relations when interpreting a familiar speech into their second language than when interpreting an unfamiliar speech into their first language; only one interpreter (A1m) is more successful when interpreting the unknown speech into his first language than when interpreting the known topic into his second language. 


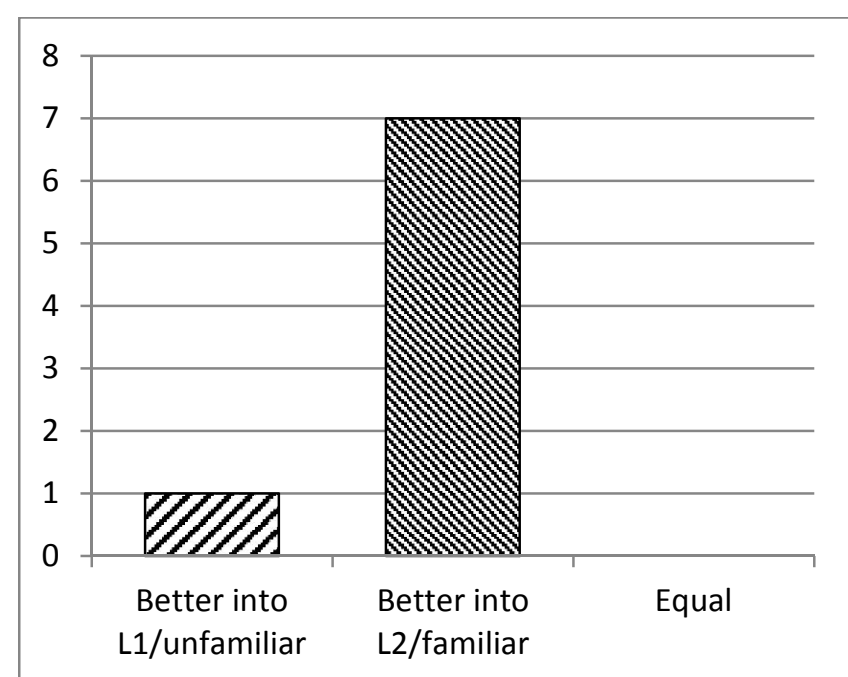

Figure 4a. Number of interpreters performing better during L1 interpreting of unfamiliar topic and L2 interpreting of familiar topic

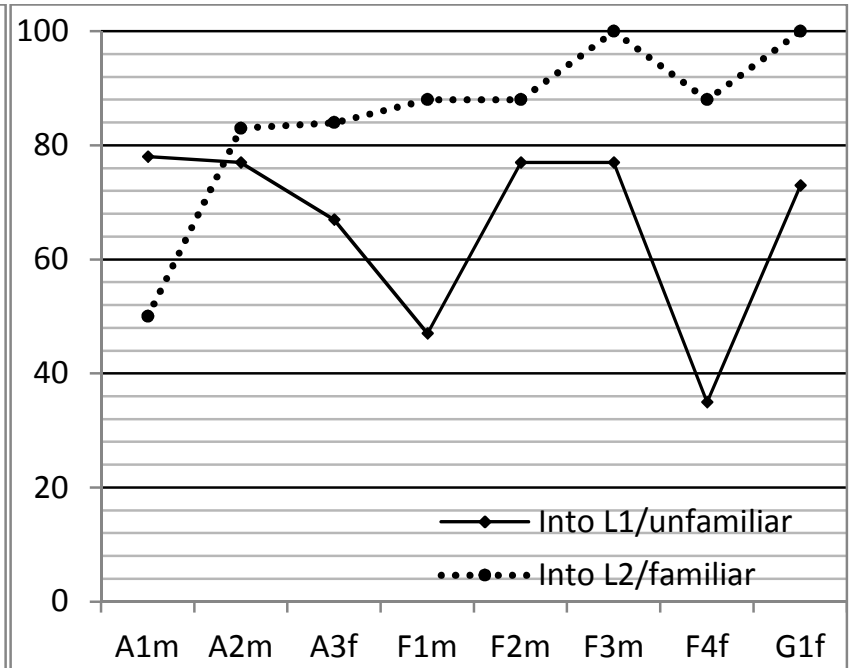

Figure 4b. Successful strategies (in \%) for L1 interpreting of unfamiliar topic and L2 interpreting of familiar topic

This finding, illustrated by Figures $4 \mathrm{a}$ and $4 \mathrm{~b}$ above, indicates that familiarity with the topic of the speech to be interpreted usually has a greater effect on the interpreters' performance than interpreting direction, and clearly outweighs any effects of interpreting direction. Most of the interpreters are found to be more successful when rendering a speech on a familiar topic into their second language than when rendering a speech on an unfamiliar topic into their first language ${ }^{4}$. Familiarity with the topic therefore appears to offset the advantages of any one interpreting direction as far as the successful recreation of source speech cohesive networks is concerned.

\section{Conclusion}

In conclusion, interpreting direction appears not to be the main predictor of interpreters' success in the transfer of source speech cohesive devices; this feature of interpreters' output appears instead to be affected by other, extralinguistic factors such as interpreters' familiarity with the topic of the speech to be interpreted. Regarding the recreation of source speech cohesive ties, interpreting direction is therefore not a relevant factor in predicting interpreting performance. Instead, interpreters consistently perform better when they are familiar with the topic of the source language speech. The assumption that the effects of other, extralinguistic factors on interpreter performance may be much less significant than the effects of language mastery (Gile 2005:17) therefore proves to hold true for the small corpus examined in the present study.

This finding may explain why the different studies on directionality in interpreting, discussed in section 2, often appear to contradict one another. As participants in these studies may have different levels of familiarity with the specialised contexts of the speeches that they are interpreting, the performances recorded for first- and second-language interpreting across different studies (or within the same study) may vary.

\footnotetext{
${ }^{4}$ This finding may furthermore imply that interpreters' context familiarity compensates more for the presumed gap in second-language production skills during second-language interpreting (as theorised by Setton 2004) than it does for the presumed gap in second-language comprehension skills during first-language interpreting.
} 
Although it has been shown that the cohesion of the interpreter's target language output can be affected by interpreting direction (Gumul 2006), it may be argued that this specific variable is likely to be influenced more strongly by his or her familiarity with the specialised context of the source language speech than by interpreting direction, for obvious reasons: an interpreter who has some extent of familiarity with a certain topic is more likely to know whether the relation between two clauses is adversative or causal in nature. Nonetheless, interpreters' success at recreating source speech cohesive ties in their target language output is a highly relevant factor in determining the quality of the interpreted product in the eyes of both professional interpreters and different types of listeners (Kurz 1993). It is possible, but it remains to be determined whether familiarity with the topic (and other extralinguistic variables) also has similar effects on elements other than the recreation of cohesive relations.

The above finding holds implications for interpreter training as well as professional practice. Regarding training, it appears recommendable to provide interpreters with subject-specific training and/or techniques for dealing with speeches on entirely unfamiliar topics. Regarding professional interpreting practice, it has become clear that interpreters' native and non-native languages should not be the sole criterion under consideration when selecting interpreters for an assignment, as other factors, and in particular interpreters' level of familiarity with the topic of the speech to be interpreted, may prove much more relevant to interpreting performance.

\section{References}

Al-Salman, S. and R. Al-Khanji. 2002. The native language factor in simultaneous interpretation in an Arabic/English context. Meta 47(4): 607-626.

Anderson, L. 1994. Simultaneous interpretation: Contextual and translation aspects. In S. Lambert and B. Moser-Mercer (eds.) Bridging the gap. Empirical research in simultaneous interpretation. Amsterdam and Philadelphia: John Benjamins. pp. 101-120.

Barik, H.C. 1994. A description of various types of omissions, additions and errors of translation encountered in simultaneous interpretation. In S. Lambert and B. Moser-Mercer (eds.) Bridging the gap. Empirical research in simultaneous interpretation. Amsterdam and Philadelphia: John Benjamins. pp. 121-137.

Barlow, M. 2003. ParaConc: A concordancer for parallel texts. (Draft 3/03). Available online: http://www.athel.com/para.html (Accessed 13 March 2012).

Bartłomiejczyk, M. 2004. Simultaneous interpreting A-B vs. B-A from the interpreters' standpoint. In D. Gile, G. Hansen and K. Malmkjær (eds.) Claims, changes and challenges in translation studies: Selected contributions from the EST Congress, Copenhagen 2001. Amsterdam/Philadelphia: John Benjamins. pp. 239-249.

Blum-Kulka, S. 1986/2002. Shifts in cohesion and coherence in translation. In L. Venuti (ed.) The translation studies reader. London: Routledge. pp. 290-305.

Chang, C. 2005. Directionality in Chinese/English Simultaneous Interpreting: Impact on Performance and Strategy Use. PhD dissertation, University of Texas. 
Darò, V., S. Lambert and F. Fabbro. 1996. Conscious monitoring of attention during simultaneous interpretation. Interpreting 1(1): 101-124.

Denissenko, E. 1989. Communicative and interpretative linguistics. In L. Gran and J. Dodds (eds.) The theoretical and practical aspects of teaching conference interpretation. Udine: Campanotto. pp. 155-157.

Donovan, C. 2002. Survey of users: Expectations and needs. In Teaching Simultaneous Interpretation into $a$ ' $B$ ' Language. Available online: http://www.emcinterpreting.org/ ?q=system/files/EMCI-TeachingSimultaneousIntoB-voll.pdf (Accessed 28 March 2013).

Donovan, C. 2004. European Masters Project Group: Teaching simultaneous interpretation into a B language. Preliminary findings. Interpreting 6(2): 205-216.

Gile, D. 1990. L'évaluation de la qualité du travail par les délégués: Une étude de cas. The Interpreters' Newsletter 3: 66-71.

Gile, D. 1993. Translation/interpretation and knowledge. In Y. Gambier and J. Tommola (eds.) Translation and knowledge. SSOTT IV: Scandinavian Symposium on Translation Theory, Turku. Turku: Centre for Translation and Interpreting, University of Turku. pp. 67-86.

Gile, D. 2005. Directionality in conference interpreting: A cognitive view. In R.M. Godijns and M. Hinderdael (eds.) Directionality in interpreting: The "retour" or the native? Gent: Communication and Cognition. pp. 9-26.

Gumul, E. 2006. Explicitation and directionality in SI. Available online: http://www.emcinterpreting.org/repository/ppt/UoW_conf_06-E.Gumul.ppt (Accessed 11 February 2012).

Harris, B. 1989. Norms in interpretation. Target 2(1): 115-119.

Kalina, S. 2005. Quality in the interpreting process: What can be measured and how? Communication and Cognition 38(1-2): 27-46.

Kurz, I. 1993. Conference interpreting. Expectations of different user groups. In F. Pöchhacker and M. Shlesinger (eds.) The interpreting studies reader. London: Routledge. pp. 313-324.

Kurz, I. and B. Färber. 2003. Anticipation in German-English simultaneous interpreting. Forum 1(2): 123-150.

Marian, V., H.K. Blumenfeld and M. Kaushanskaya. 2007. The Language Experience and Proficiency Questionnaire (LEAP-Q): Assessing language profiles in bilinguals and multilinguals. Journal of Speech Language and Hearing Research 50(4): 940-967.

Olohan, M. and M. Baker. 2000. Reporting that in translated English: Evidence for subliminal processes of explicitation? Across Languages and Cultures 1(2): 141-158.

Seleskovitch, D. 1978. Interpreting for international conferences. Washington: Pen and Booth. 
Setton, R. 2004. New demands on interpreting and the learning curve in interpreter training. In C. Mingjiong and Z. Jiliang (eds.) Proceedings of the Fifth National Conference on Interpreting Practice, Pedagogy, and Research, SISU, Shanghai, November 2004. Shanghai: Shanghai Waiju jiaoyu chubanshe. pp. 1-20.

Setton, R. 2006. Context in simultaneous interpretation. Journal of Pragmatics 38(3): 374-389.

Shlesinger, M. 1995. Shifts in cohesion in simultaneous interpreting. The Translator 1(2): 193214.

SSLMIT (Scuola Superiore di Lingue Moderne per Interpreti e Traduttori, University of Bologna). 2004. EPIC transcription conventions. Available online: http://sslmitdevonline.sslmit.unibo.it/corpora/additionalpages.php?path=E.P.I.C.\&source=project\&content=tr anscription_conventions.desc (Accessed 14 December 2009).

Tommola, J. and M. Helevä. 1998. Language direction and source text complexity: Effects on trainee performance in simultaneous interpreting. In L. Bowker, M. Cronin, D. Kenny and J. Pearson (eds.) Unity in diversity? Current trends in translation studies. Manchester: St. Jerome. pp. 177-186.

Tommola, J. and T. Laakso. 1997. Source-text segmentation, speech rate and language direction. Effects on trainee simultaneous interpreting. In K. Klaudy and J. Kohn (eds.) Transferre necesse est. Proceedings of the Second International Conference on Current Trends in Studies of Translation and Interpreting. Budapest: Scholastica. pp. 186-191.

Viaggio, S. 1994. The interaction between research and the profession: Training. In Y. Gambier, D. Gile and C. Taylor (eds.) Conference interpreting: Current trends in research. Amsterdam/Philadelphia: John Benjamins. pp. 102-104.

Vuorikoski, A.R. 2004. A Voice of its Citizens or a Modern Tower of Babel? PhD dissertation, University of Tampere. Available online: http://tampub.uta.fi/handle/ 10024/67348 (Accessed 3 August 2013). 